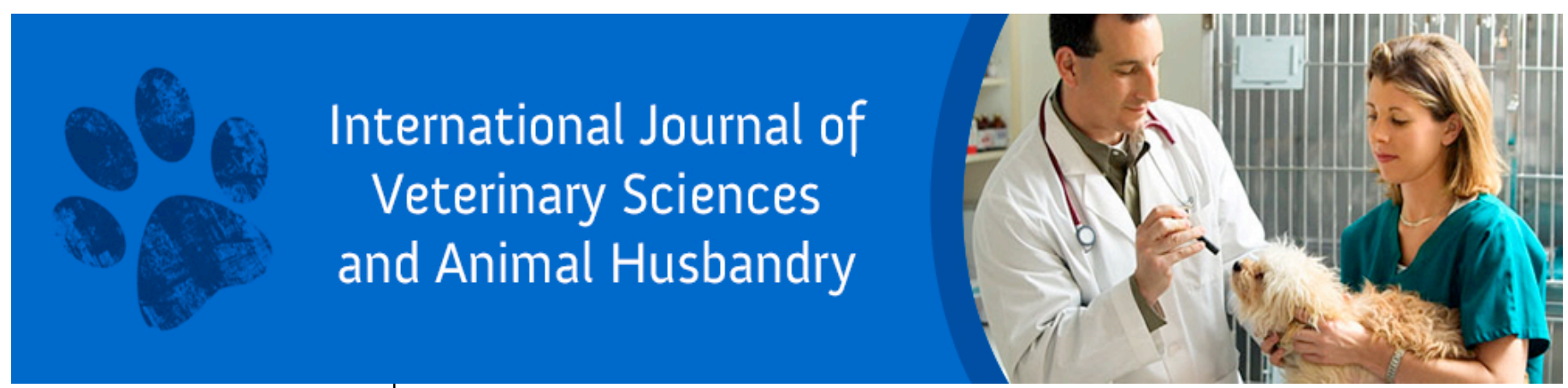

ISSN: 2456-2912

VET 2020; 5(6): 11-13

(C) $2020 \mathrm{VET}$

www.veterinarypaper.com

Received: 03-09-2020

Accepted: 16-10-2020

\section{Andreia Garcês}

Inno - Serviços Especializados em Veterinária, R. Cândido de Sousa, Braga, Portugal

\section{Justna Prada}

CECAV, University of Trás-osMontes and Alto Douro, Quinta de Prados, Vila Real, Portugal.

\section{Isabel Pires}

CECAV, University of Trás-osMontes and Alto Douro, Quinta de Prados, Vila Real, Portugal.

Corresponding Author: Andreia Garcês

Inno - Serviços Especializados em Veterinária, R. Cândido de Sousa, Braga, Portugal

\section{SARS-CoV-2 and animals: What we known!}

\author{
Andreia Garcês, Justna Prada and Isabel Pires
}

DOI: https://doi.org/10.22271/veterinary.2020.v5.i6a.304

\section{Abstract}

In December 2019 emerged in Wuhan (China), an outbreak of fatal pneumonia, caused by the SARSCoV-2, that rapidly became a pandemic infecting million worldwide. This virus had its origin on wild animals, although its transmission and mutations are still not very clear. Questions are rising with the development of the pandemic: if a reverse zoonosis could occur, could humans affected other animals' species and those infect other species and humans. Since the begging of the pandemic there has been a few reports from around the world of animals being infected with SARS-CoV-2 and none from animals to humans. The virus has become a concern by its impacts on animals' health. We need to adapt and promote sustainable measures for the management of the environment and animals under a 'One Health' movement.

Keywords: virus, SARS-cOv-2, animals, zoonoses.

\section{Introduction}

In December 2019 emerged in Wuhan (China) an outbreak of fatal pneumonia of unknown origin. Genetic and molecular analysis revealed that the causative agent was a coronavirus, and the disease was denominated Severe Acute Respiratory Syndrome-Coronavirus-2 (SARSCoV-2), and more commonly as COVID-19 by the World Health Organization (WHO) ${ }^{[1-3]}$. Rapidly the virus spread to other countries through travelers and on March 11, 2020, WHO declared COVID-2019 as a pandemic. On October 2020, the epidemy had already more than 34 million confirmed cases of infected people across more than 216 reported countries, where 1030,000 people died as reported to $\mathrm{WHO}{ }^{[4]}$.

This pandemic is a severe reminder of the imminent global threat from emerging infectious diseases and zoonoses, since the last great pandemic, the 1918 Spanish flu that occurred a little more than 100 years ${ }^{[5]}$. The epicenter of the outbreak was been determined as Huanan seafood market, and there is a high possibility that the patient zero had to be infected through zoonotic or environmental exposures due to the sale of wild animals to human consumption and traditional medicine ${ }^{[5,6]}$.

Several species harbors coronavirus, from humans, domestic and wild species. The severity of the infection can be quite diverse, with the majority being sub-clinical and, in some cases, leading to severe infections and death ${ }^{[1,7]}$. There are four genera in the Coronaviridae family: Alphacoronavirus, Betacoronavirus, Gammacoronavirus and Deltacoronavirus. Alphacoronaviruses and betacoronaviruses infect bats and other mammals only, whereas gammacoronaviruses and deltacoronaviruses infect birds, mammals and marine animals ${ }^{[1,6]}$.

Veterinarians have already a great experience in dealing with coronavirus. infectious bronchitis virus (IBV) in chickens, porcine respiratory coronavirus (PRCoV), swine acute diarrhoea syndrome coronavirus (SADS-CoV), equine CoVs (ECoVs), bovine coronavirus (BCoV), canine respiratory coronavirus (CRCoV), feline infectious peritonitis virus (FIPV) and feline enteric coronavirus (FECV) are some examples of the CoVs circulating on the animals' populations ${ }^{[6]}$. The newly identified SARS-CoV-2 belongs to the genus Betacoronavirus. Genetic sequence data has revealed that SARS-CoV-2 seems to be genetically closely related to other coronaviruses circulating in Rhinolophus bat (horseshoe bat) populations (96.2\% similar to a bat coronavirus RaTG13 (BatCoV RaTG13). But still, 
there is not enough scientific evidence to identify the source of SARS-CoV-2 or to explain the original route of transmission to humans, if it has occurred directly from the bats or there are some intermediate hosts involved. Based on the isolation of CoV Malayan pangolins (Manis javanica), these animals are thought to be intermediate hosts and where the virus adapted to humans via natural selection ${ }^{[2,3, ~ 5, ~ 6, ~ 8, ~ 9] . ~}$ Questions are rising with the development of the pandemic: if a reverse zoonosis could occur, could humans affected other animals' species and those infect other species and humans. These questions rise countless concerns to the WHO, but also the veterinary community.

\section{Natural infection of SARS-CoV-2 in animals}

Since the begging of the pandemic, there have been a few reports from around the world of animals being infected with SARS-CoV-2. The first confirmed reports of pets infected with SARS-CoV-2 came from Hong Kong, two dogs that live with COVID-19 patients tested positive ${ }^{[10]}$. To the moment little cases of infected dogs have been reported on Hong Kong (2), Netherlands (1) and the US (14) ${ }^{[4,11]}$. The studies present to the date show that although dogs can be naturally infected by SARS-CoV-2 there is low susceptibility, and only some cases present mild symptoms ${ }^{[12]}$.

Regarding felines, a few cases have been reported in pets and big cats in captivity. Cats appear to be highly susceptible to the virus contrary to dogs ${ }^{[10]}$. Cases in domestic cats have been reported from reported in Hong Kong (1), Spain (1), Netherlands (10), Belgium (2), France (1), and Germany (1), Russia and the US (12) ${ }^{[2,8,13,14]}$. Some of the animals became clinically ill, exhibiting respiratory problems (sneezing, clear ocular discharge, coughing, watery nasal and ocular discharge) accompanied by diarrhoea and vomiting. In New York (US) a Malayan tiger (Panthera tigris. jacksoni) tested positive for the disease due to the association with a COVID19-positive zoo employee. Later, the other 6 animals that lived in the same enclosure (1 Malayan tiger (Panthera tigris jacksoni), 2 Amur tigers (Panthera tigris altaica) and 3 African lions (Panthera leo krugeri) also tested positive. They developed clinical signs of respiratory disease but all recovery well ${ }^{[1,14,16]}$ (Fig. 1)

Minks (Neovison vison) present a high susceptibility to SARS-CoV-2. Several outbreaks have been reported on farms on Netherlands, Spain, US. The animals showed an increased incidence of gastrointestinal and respiratory disease and overall mortality. The source of transmission is most likely to have been one of the caretakers, and there is the possibility that cats were involved in the transmission of the virus

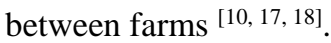

The infection on animals' results of close contact with humans infected with SARS-CoV-2. However, although is known the origin of the virus is from animals, there is no case of animals that infected humans [1, 3, 8, 19]. The routes of transmission of SARS-CoV-2 among animals appears to be animal to animal by direct contact similar to what has been observed in humans ${ }^{[3,4]}$.

\section{Experimental infection of SARS-CoV-2 in animals}

Since the beginning of the pandemic, susceptibility to COVID-19 has been assessed in vitro in several species of animals in an attempt to identify animal models of SARSCoV-2 infection (Fig. 1). Among laboratory animals, ferrets, golden Syrian hamsters, fruits bats, raccoon dogs, and monkeys have been shown to be susceptible to SARS-CoV-2, and they develop clinical symptoms [7, 10, 19, 20]. In experimental infections, pigs, chickens, and ducks remained SARS-CoV-2 negative and did not develop any clinical signs (Fig. 1) ${ }^{[2,13,19,21,22] .}$

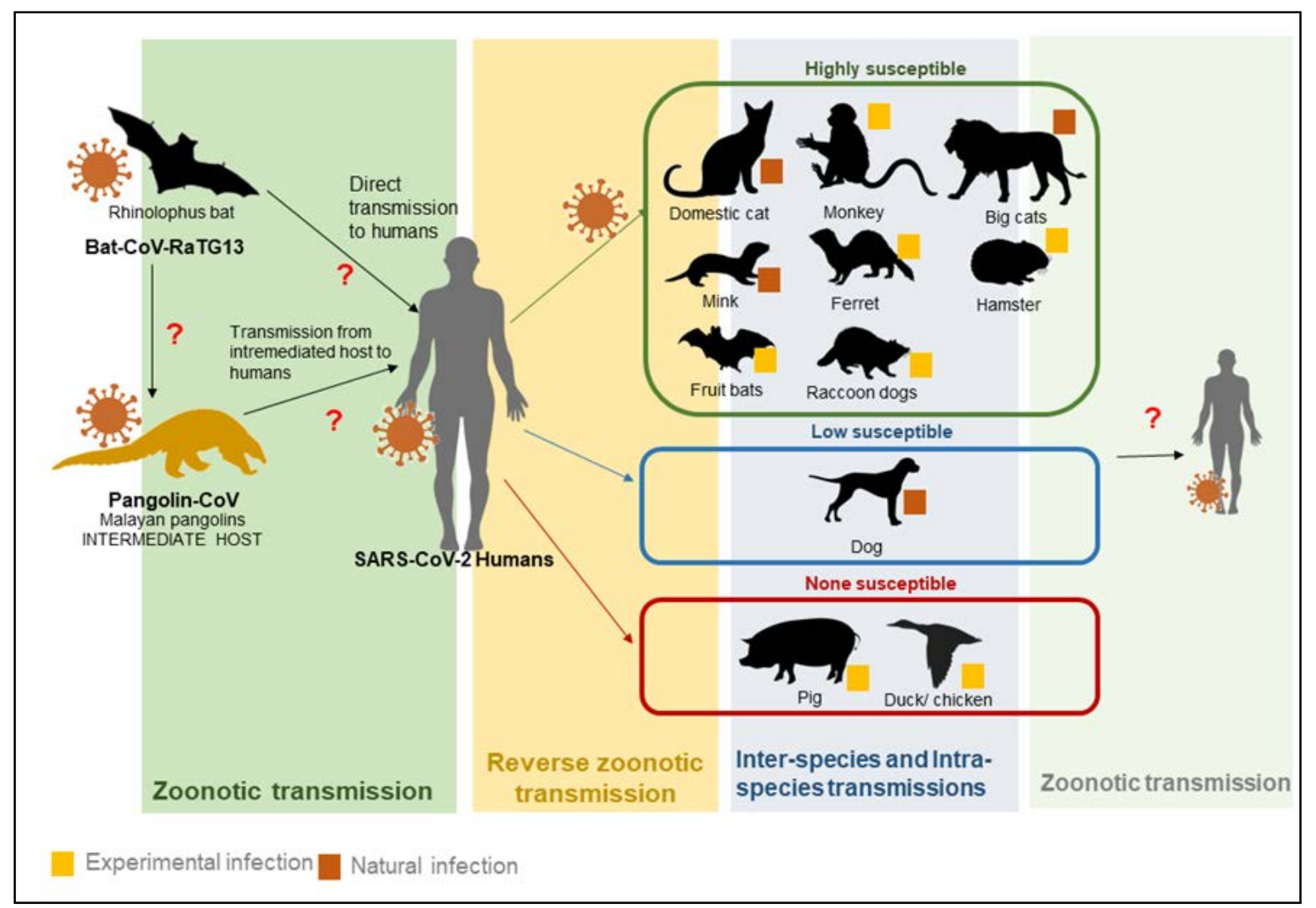

Fig 1: Possible origin of SARS-CoV-2 and transboundary transmissions between humans and animals (SARS-CoV-2: severe acute respiratory syndrome coronavirus-2; Bat-CoV: bat coronavirus; Pangolin-CoV: pangolin coronavirus). 


\section{Discussion and final conclusions}

The great concern at this moment it is if will occur a reverse zoonosis, and due to some animal-to-human interaction, the virus can transmit both ways. If this occurs and the virus establishes itself in humans and animal populations it'll be really hard to eradicate. Those concerns already driven authorities on countries as Netherlands and Spain to cull all the minks on farms where the SARS-CoV-2 has been found, to ensure that they do not become reservoirs for the virus. Similar measures can have a tremendous impact on wild populations and also in the economy with the elimination of thousands of production animals (although the majority of the species, as pigs and cattle, seems resistant to the virus).

Another important question that rises to veterinarians, is how the virus is going to affect the health of animals, particularly domestic animals as cats and dogs. After stablish on the animal's population will be a problem. As example could be similar to feline infectious peritonitis virus (FIPV). If so, we need to start thinking in develop not only vaccination to human population, but also to the animals more severe affected.

As global population growth, also the destruction of animal habitats, production of wastes and consumption of traditional and non-traditional meats will continue. This will inevitably lead to outbreaks of zoonotic diseases that will cross the animal-human barrier. COVID-19 remind us that systems and precautions that should have been in place to prevent a global pandemic of this extent have failed. Now is important to rethink how human is exploring the planet. We need to adapt and promote sustainable measures for the management of the environment and animals under a 'One Health' movement.

\section{References}

1. Tiwari R, Dhama K, Sharun K, Iqbal Yatoo M, Malik YS, Singh R, et al. COVID-19: animals, veterinary and zoonotic links. Vet Q [Internet] 2020;40(1):169-82.

2. Vinodh Kumar OR, Ramkumar, Pruthvishree BS, Pande T, Sinha DK, Singh BR, et al. SARS-CoV-2 (COVID19): Zoonotic origin and susceptibility of domestic and wild animals. J Pure Appl Microbiol. 2020;14(1):741-7.

3. Mahdy MAA. An overview of SARS-CoV-2 and animal infection. Preprints 2020;(April):1-14.

4. WHO. WHO Coronavirus Disease (COVID-19) Dashboard | WHO Coronavirus Disease (COVID-19) Dashboard [Internet] 2020. [cited 2020 Aug 29]. Available from: https://covid19. who.int/?gclid=Cj0KCQjwaf6BRC5ARIsAALPIIWX9XLNaFPKAeHQo7fdQFmK 5vsBEi477Sf8dBr_teU6MPQ9_jSY3osaAvf2EALw_wc B

5. Konda M, Dodda B, Konala VM, Naramala S, Adapa S. Potential Zoonotic Origins of SARS-CoV-2 and Insights for Preventing Future Pandemics Through One Health Approach. Cureus 2020;(June).

6. Poudel U, Subedi D, Pantha S, Dhakal S. Animal coronaviruses and coronavirus disease 2019: Lesson for one health approach. Open Vet J 2020;10(3):239-51.

7. Malik YS, Sircar S, Bhat S, Vinodhkumar OR, Tiwari R, Sah R, et al. Emerging coronavirus disease (COVID-19), a pandemic public health emergency with animal linkages: Current status update. Indian J Anim Sci 2020;90(3):158-73.

8. Sailleau C, Dumarest M, Vanhomwegen J, Delaplace M, Caro V, Kwasiborski A, et al. First detection and genome sequencing of SARS-CoV-2 in an infected cat in France. Transbound Emerg Dis 2020, 0-1.

9. Zhou P, Yang X Lou, Wang XG, Hu B, Zhang L, Zhang $\mathrm{W}$, et al. A pneumonia outbreak associated with a new coronavirus of probable bat origin. Nature 2020;579(7798):270-3.

10. Yoo HS, Yoo D. COVID-19 and veterinarians for one health, zoonotic- and reverse-zoonotic transmissions. J Vet Sci 2020;21(3):e51.

11. Yoon BI, Lee JK, Kim JH, Shin NS, Kwon SW, Lee GH, et al. Lymphosarcoma in a brown bear (Ursus arctos). J Vet Sci. 2001;2:143-5.

12. Health WO for A. Technical Factsheet Infection With Sars-Cov-2 in Animals 2020, Vol 2.

13. O' Connor AM, Totton SC, Sargeant JM. A rapid review of evidence of infection of pets and livestock with human-associated coronavirus diseases, SARS, MERS, and COVID-19, and evidence of the fomite potential of pets and livestock. Syst Rev Anim food 2020;0(0).

14. Sharun K, Sircar S, Malik YS, Singh RK, Dhama K. How close is SARS-CoV-2 to canine and feline coronaviruses? J Small Anim Pract [Internet] 2020;61(8):523-6.

15. McAloose D, Laverack M, Wang L, Killian ML, Leonardo, Caserta C, et al. From people to Panthera: Natural SARS-CoV-2 infection in tigers and lions at the Bronx Zoo 2019;53(9):1689-99.

16. Wang L, Mitchell PK, Calle PP, Bartlett SL, McAloose $\mathrm{D}$, Killian $\mathrm{ML}$, et al. Complete Genome Sequence of SARS-CoV-2 in a Tiger from a U.S. Zoological Collection. Microbiol Resour Announc 2020;9(22):1-3.

17. Molenaar RJ, Vreman S, Hakze-van der Honing RW, Zwart R, de Rond J, Weesendorp E, et al. Clinical and Pathological Findings in SARS-CoV-2 Disease Outbreaks in Farmed Mink (Neovison vison). Vet Pathol, 2020, 1-5.

18. Oreshkova N, Molenaar RJ, Vreman S, Harders F, Oude Munnink BB, Van Der Honing RWH, et al. SARS-CoV2 infection in farmed minks, the Netherlands, April and May 2020. Eurosurveillance 2020;25(23).

19. Khan S, Patel SK, Karthik K, Veterinary TN. Coronavirus disease 2019 ( COVID-19 ) in domestic animals and wildlife: advances and prospects in the development of animal models for vaccine and therapeutic research Coronavirus disease 2019 (COVID19 ) in domestic animals and wildlife: advances and. Hum Vaccin Immunother 2020;0(0).

20. Schlottau K, Rissmann M, Graaf A, Schön J, Sehl J, Wylezich C, et al. SARS-CoV-2 in fruit bats, ferrets, pigs, and chickens: an experimental transmission study. The Lancet Microbe 2020;0(0).

21. Lee JR, Lee JR, It I, Acquisition C, Support L, Muhammad Yogi, et al. Pathogenesis, transmission and response to re-exposure of SARS-CoV-2 in domestic cats 2. 第一财经日报 2020;53(1):1-9.

22. Freuling CM, Breithaupt A, Müller T, Sehl J, BalkemaA, Aebischer A, et al. Raccoon dogs are susceptible to and efficiently transmit SARS-CoV2 and may serve as intermediate host 2020, 0(0). 